\title{
Critical Discourse Analysis as an Analytical Resource for Cultural Studies: Exploring the Discursive Construction of Subject Positions in British Men's Magazines' Problem Pages
}

\author{
Eduardo de Gregorio Godeo \\ University of Castilla-La Mancha \\ Eduardo.Gregorio@uclm.es
}

\begin{abstract}
In operating with quite an abstract approach to 'discourse', cultural studies has hardly engaged in detailed textual analyses examining the role of language and discourse in the constitution of cultural processes. By focusing on an area of concern for contemporary cultural studies such as the discursive construction of subject positions, this paper casts light on the instrumental role that critical discourse analysis (henceforth CDA) may play as an analytical resource for cultural studies. In particular, we highlight how detailed textual analyses undertaken by CDA may contribute to deciphering the role of language and discourse in the articulation of cultural practices of identity representation and construction in media discourse. After revising the coincidences on the agendas of CDA and cultural studies, a case study follows exploring the discursive construction of such a subject position on masculinity as the so-called 'new man' in a sample from men's magazines' problem pages as a characteristic popular-culture genre in contemporary Britain. Our analysis substantiates the valididy of Fairclough's CDA framework for disentangling the mechanisms of identity construction in this genre of present-day media discourse in the UK.
\end{abstract}

\section{Introduction}

In operating with quite an abstract approach to 'discourse', cultural studies has hardly attempted to disentangle how linguistic-discursive dimensions work in the constitution of 
cultural processes and phenomena by undertaking detailed analyses of actual discourse (Grossberg, 1997; Barker and Galasinski, 2001; Barker, 2002). By focusing on an area of concern for contemporary cultural studies such as the discursive construction of subject positions, this paper means to cast light on the instrumental role that critical discourse analysis (henceforth CDA) may play as an analytical resource for cultural studies. In particular, we will highlight how detailed textual analyses undertaken by CDA may be able to decipher the role of language and discourse in the articulation of cultural practices of identity representation and construction in media discourse. Thus, after revising the coincidences on the agendas of CDA and cultural studies, a case study will follow exploring the discursive construction of such a masculinity subject position as the so-called 'new man' in a sample from men's magazines' problem pages as a characteristic popular-culture genre in contemporary Britain. Our analysis will substantiate the valididy of Fairclough's CDA framework - as implemented in the case study - for examining this process of identity construction in this genre of contemporary media discourse in the UK.

\section{CDA and cultural studies at the crossroads}

The domain of cultural studies may be understood "as an interdisciplinary or postdisciplinary field of enquiry that explores the production and inculcation of culture or maps of culture" (Barker, 2004: 42). Taking a recent approach to the term, Blommaert sees CDA as "a linguistically oriented discourse analysis firmly anchored in social reality and with a deep interest in actual problems and forms of inequality in societies" (2005: 6) . According to Wodak, the term CDA is used nowadays to refer

to the critical linguistic approach of scholars who find the larger discursive unit of text to be the basic unit of communication. This research specifically considers institutional, political, gender and media discourses [...] which testify to more or less overt relations of struggle and conflict (2001: 2).

Echoing Chouliaraki and Fairclough's (1999) attempt at firmly anchoring CDA on social theory, Blommaert has thus recently underlined a remarkable coincidence on the agendas of cultural studies and CDA, for the latter "continually but critically engages with new research trends in, for example, postmodern, feminist, postcolonial, and globalisation studies" (2005: 28) ${ }^{1}$.

'Discourse' has become a key notion within contemporary cultural theory (Baldwin et al., 1999; Lewis, 2002). Following the strong influence of theorists like Michel Foucault and post-structuralism upon the field, a widespread approach to discourse in cultural studies has come to signal "ways of speaking about the world of social experience [...] A discourse on this view, is a means of both producing and organising meaning within a social context" (Edgar and Sedgwick, 1999: 117). Nonetheless, although discourse may be claimed to be a vital concept for cultural studies, it is often the case that "in the end, it [cultural studies] 
is not interested in the discourse per se but in the articulations between everyday life and the formations of power" (Grossberg, 1997: 5). Indeed, cultural theory has tended to operate with quite an abstract conception of discourse, which is barely applicable to the analysis of actual samples of language, and which, consequently, has not been able to disentangle how actual linguistic usage contributes to the articulation of specific cultural practices in society. As Barker and Galasinski argue in an attempt to bridge the gap between cultural studies and discourse analysis,

Though cultural studies has produced a large body of textual analysis and made claims regarding the social construction of gender, ethnicity, class, age, etc., it has only rarely attended to the day-to-day speech of acculturated persons. Consequently, cultural studies has been unable to show how precisely the discursive construction of cultural forms is achieved in everyday life (2001: 27).

Nonetheless, a number of coincidences on the agendas of CDA and cultural studies may reveal the fundamental role that CDA may play as an instrumental resource for cultural studies insofar as capable of unravelling processes of language and culture interaction by means of detailed textual analyses.

Firstly, cultural studies assumes that "language is the primary means and medium through which we form knowledge about ourselves and the social world" (Barker, 2004: 107). Following the Foucauldian conception of discourse to refer "to a unity of language and practice that defines and produces its objects of knowledge" (Barker, 2002: 27) and, as a result, an approach to "language understood as discourse" (Edgar and Sedgwick, 1999: 118), cultural studies positions itself very close to CDA's conception that "discourse -language use in speech and writing-as a form of social practice [...] is socially constitutive as well as socially shaped" (Fairclough and Wodak, 1997: 258).

Secondly, both CDA and cultural studies assume the essential function played by language and power relations in the constitution of culture. For contemporary cultural theory, "primarily, culture is concerned with the production and exchange of meanings the 'giving and taking of meaning' - between the members of a society or group" (Hall, 1997: 2); and, as Hall adds, "language is the privileged medium in which we 'make sense' of things, in which meaning is produced and exchanged" (1997: 1$)^{2}$. In addition, cultural studies has come to take shape as a discipline "concerned with the analysis of cultural forms and activities in the context of the relations of power which condition their production, circulation, deployments and, of course, effects" (Bennett, 1998: 60). In a similar way, CDA very much focuses on language and the constitution of power relations in society. As van Dijk puts it, "critical discourse analysis (CDA) is a type of discourse analytical research that primarily studies the way social power abuse, dominance, and inequality are enacted, reproduced and resisted by text and talk in the social and political context" (2001: 352). On the basis of a discursive conception of language, CDA takes for granted the constitutive nature of language with regard to society, culture and power relations. As Fairclough and Wodak stress, "discourse constitutes society and culture, as well as being 
constituted by them. Their relationship is a dialectical one. This entails that every instance of language use makes its own small contribution to reproducing and/or transforming society and culture, including power relations" (1997: 273).

Thirdly, work in both cultural studies and CDA is characterised by its significant political commitment. According to During, "cultural studies has been, as we might expect, most interested in how groups with least power practically develop their own readings of, and uses for, cultural products - in fun, in resistance, or to articulate their own identity" (1993: 7). In a similar fashion, "critical discourse analysts take explicit position, and thus want to understand, expose and ultimately resist social inequality" (van Dijk, 2001: 352).

\section{The discursive construction of subject positions: a focus on media discourse}

We have highlighted above that for cultural studies "discourse produces the meanings of the world (knowledge) in an intelligible way; we understand an object, event, person or practice because it is placed in the symbolic or discursive order" (Lewis, 2002: 25). Following the influence of Michel Foucault and post-structuralism upon the field, contemporary cultural theory assumes that, being regulated by the power relations of the social formations where they emerge, discourses create subject positions with which individuals negotiate their own personal identity, making sense of reality from that ideological perspective as well (Lewis, 2002: 95; Barker, 2002: 39; Barker, 2004: 194). As Phillips and Jørgensen (2002) reveal, this theorization of the discursive construction of subject positions has been embraced by a number of social constructionist discourse analysis perspectives, by way of example, Laclau and Mouffe or discursive psychology. From the viewpoint of discursive pshychology, Davies and Harré (1990: 46) have theorized subject positions as incorporating "both a conceptual repertoire and a location for persons within the structure of rights for those that use that repertoire [...] within the particular discursive practice in which they are positioned". Individuals become social subjects with a certain identity as they are positioned in the discourses where their social activity takes place. Identity emerges as individuals take up - or resist - the subject positions which are made available in the discourses surrounding them in the course of their social life ${ }^{3}$. For cultural theorist Stuart Hall, "identities are thus points of temporary attachment to the subject positions which discursive practices construct for us (2000: 19).

A number of discourse and cultural theorists have discussed subject positions as being specific to discourse types (e.g. Fairclough, 1989: 102; Barker, 2002: 39; Phillips and Jørgensen, 2002: 41). What characterises media discourse in this respect is the construction of 'ideal readers' - or hearers or viewers - as a special kind of subject positions with which actual media consumers will negotiate their individual identity ${ }^{4}$. As Reah underlines with reference to newspapers - which may likewise be applied to other media-discourse vehicles - "newspapers assume the existence of groups that may not actually exist as groups within society and, by addressing themselves to these groups, create a shared ideology" (1998: 
35). Following McLoughlin's exploration of the discourse of magazines, which is the case in point in this paper,

Writers of magazines are in difficulty in addressing a mass audience. They cannot claim to know the identity of each reader, yet they often speak as though they already know the reader, their thoughts, attitudes, likes and dislikes. In order to do this an imaginary addressee is constructed which I will refer to as ideal-reader" (2000: 67).

In particular, general-interest periodicals like women's magazines have been claimed to "construct an 'ideal' reader who is at the same time both produced and in a sense imprisoned by the text" (Caldas-Coulthard, 1996: 250), which may be similarly posited with regard to the sister-genre of men's magazines analysed in this contribution.

Sunderland has recently paid attention to the existence of 'gendered discourses' on the grounds that "when women and men, boys and girls are represented and/or expected to behave in particular gendered ways, post-structuralism and CDA see gendered discourses as positioning women and men in different ways, i.e. as constitutive" (2004: 21). In this regard, media discourse is one key arena for the representation and construction of gender identities in society:

This is partly because the major mass media have the power to represent, over and over, some images, some assumptions, and to exclude others, [...] One of the richest areas of discussion of representation and media forms exists around gender identities (Branston and Stafford, 1996: 78).

As discussed bellow, such a vehicle of media discourse as men's magazines have become "an important site for the articulation of aspects of modern masculinity and addressal of the masculine consumer" (Benwell, 2003: 6). It therefore seems to be a legitimate project to examine the construction of gendered subject positions in the discourses on masculinity articulated in men's magazines.

\section{Fairclough's framework of CDA}

As stated by Wodak and Ludwig, "CDA is not a homogenous theory with a set of clear and defined tools but rather a research programme with many facets and numerous different theoretical and methodological approaches" (1999: 11). Throughout the various theoretical and methodological approaches to CDA (see Fairclough and Wodak, 1997; Wodak and Meyer, 2001) underlies a concern with language in social life, deeply committed with situations of conflict and inequality in contemporary societies.

In an ever-changing framework developed in various works (e.g. Fairclough 1989, 1992, 1995a, 1995b, 2003), Fairclough's model of CDA takes shape as a distinctive one, clearly differentiated from other CDA approaches like Ruth Wodak's 'discourse-historical' method or van Dijk's 'socio-cognitive' model ${ }^{5}$. Fairclough's CDA approach has tended to 
lay a strong emphasis on "sociocultural change and change in discourse" (Fairclough and Wodak, 1997: 264). Given our examination of the discursive construction of masculinity in the new generation of men's magazines in Britain, we will chiefly draw upon Fairclough's $(1989,1992,1995$ a) work aiming at "disclosing the discursive nature of much contemporary social and cultural change" (Wodak, 2001:6). Nonetheless, reference will also be made to other works by Fairclough (e.g. 1995b, 2003), bearing specially in mind his exploration of issues in media discourse, which is central to this contribution.

In implementing what has been labelled as a characteristic "fusion of linguistics and cultural theory" (Mills, 1997: 10), Fairclough's CDA approach is characterised by a simultaneously three-fold consideration of discourse, where "discourse, and any specific instance of discursive practice, is seen as simultaneously (i) a language text, spoken or written, (ii) discourse practice (text production and text interpretation), (iii) sociocultural practice" (Fairclough, 1995a: 97). Analyses of actual discourses will focus on (i) the description of the textual dimension of discourse; (ii) the interpretation of the interaction or discursive practice; and (iii) the explanation of discourse insofar as socio-cultural action resulting from a given social matrix and embodying a certain ideology.

As Martín Rojo et al. claim, "research on CDA attempts to delve into the discursive construction of reality, social relations and the subject itself" (1998: 11; our translation). CDA has thus actively engaged in issues to do with identity construction in various sociocultural domains (e.g. van Dijk 1991; Wodak et al. 1999). Since the early formulations of his CDA model, Fairclough maintains that "discourse contributes first of all to the construction of what are variously referred to as "social identities" (1992: 64). Being indebted to the work of poststructuralism in the formulation of his framework of CDA as drawn upon in this paper - Fairclough incorporates the notion of 'subject positions' in his model, and maintains that "the socialization of people involves them coming to be placed in a range of subject positions, which they are exposed to partly to operate within various discourse types" (2001: 85). This positioning process is particularly relevant when it comes to media discourse, for

The wider social impact of media is not just to do with how they selectively represent the world, though that is a vitally important issue; it is also to do with what sorts of identities, what versions of 'self', they project and what cultural values [...] these entail (1995b: 17).

As evidenced by Fairclough's investigation of the discursive construction of identities in various media-discourse genres (e.g. Thatcher (1989), guests in Oprah Winfrey's Show (1995b) or 'New Labour' political figures (2000)), his CDA framework proves to be an appropriate instrument for disentangling the discursive construction of subject positions in media discourse. 


\section{Men's magazines, problem pages and the 'new man' in Britain}

A decade after they had started being published, men's lifestyle magazines had become the fastest-growing magazine sector in Britain (Cf. Smith, 1996: 1-2). According to Jackson et al. (2001: 30), this tendency has continued to date, so that by the late nineties titles like $F H M$ were reaching a circulation of over 500,000 items per month. This print-media sector includes titles such as Arena, Esquire, FHM, Front, GQ, Maxim, Men's Health or Stufffor Men. Such periodicals are sold on a monthly basis at a price of two to three pounds. Edwards has defined the ideal readers of these publications as "a quite specific and often fixed targeting of single, affluent, city-dwelling, high-earning and high-spending, primarily heterosexual men to the exclusion of all others: that is, all those who do not at least primarily aspire to this way of living or its values" (1997: 76). Moreover, as proves Mort's (1988: 211) and Smith's (1996: 32) market research, these general-interest magazines are aimed at a 25- to 35-year-old reader.

In addition to interviews with famous male icons and celebrities, these magazines incorporate various features to do with sport, health and fitness, sex and women, travel, art and male fashion. Advertising is also highly prominent, with a great deal of pages about male clothing and accessories, tobacco, alcohol and technology. In the majority of these publications, problem pages are a recurrent feature where male readers ask questions about a wide range of topics to do with the masculine lifestyle. Following the long-standing tradition of 'agony aunts' in women's magazines, counsellors provide readers with advice about relationships with girlfriends and wives, emotional dilemmas, health and fitness, body care and grooming, masculine fashion, etc.

In this socio-cultural context, the 'new man' has become an outstanding subject position in the discourses on masculinity circulating in contemporary Britain. This masculinity image has been claimed to represent "the ideal partner for the modern, liberated, heterosexual woman, [...] a softer, more sensitive and caring individual, who also avoids sexist language, changes nappies and loves to shop all day for his own clothes" (Edley and Wetherell, 1997: 204). Together with a more committed role as a father and a deeper contact with his feelings and emotions, since it first appeared in the eighties, this figure has been defined by his deep concern about personal looks and a remarkable attempt to approach the feminine universe and deal with women in egalitarian terms: "the New Man arose as a primarily media-driven phenomenon in the 1980 s [...] a new form of masculinity that was more caring, nurturing and sensitive - or, alternatively, more narcissistic, passive and introspective" (Edwards, 1997: 39). Nixon emphasizes the major role of men's magazines in representing and constructing such masculine-identity model, so that "if we think about the contemporary 'new man' images, it is clear that press and television advertising and consumer magazines played an important role in helping to construct this regime" (1997: 327). All in all, the 'new man' is to be understood as a media construction in different popular-culture artefacts of contemporary Britain, men's magazines and problem pages included. 


\section{Case study: The discursive construction of the 'new man' in a men's magazine's counselling column}

In order to explore the discursive construction of the 'new man' in men's lifestyle magazines' counselling columns, we proceed to analyse closely a sample from $G Q$ problem page (see final appendix). This case study will accordingly serve to highlight this identityconstruction process on various discursive layers ${ }^{6}$. Following Fairclough's CDA framework, the 'new man' will be examined as constructed at a textual, interaction, and socio-cultural level.

\subsection{Describing the textual construction of the 'new man'}

Various textual features come to construct the male reader in harmony with the ideological apparatus of 'new men' and their "increasing sense of anxiety concerning the imagery in relation to how they look" (Edwards, 1997: 130). To begin with, lexical classification schemes are articulated on the basis of such a dimension of men's fashion and dressing codes as the most appropriate way of wearing shirts (e.g. formal spread-collar shirts; tieless; open to the sternum; button-down shirts [twice]; open at the neck; ties; open-collar shirt; casual weekend shirt; with button cuffs; made in an Oxford cotton; reappearance of the male cleavage; polite society). Words like style, criteria, acceptable, formal, polite society, most usual or casual reveal the existence of strict regulations governing masculine dressing habits. In fact, the repetition of lexical items like wear (wearing / worn [twice] / wearer) or look (three times) constructs men and masculinity as subject to such fashion policies, as evidenced by the use of louche twice. Also, the explicit allusion to the market and advertising campaigns situates men as fundamental actors within the menswear business.

This construction of the reader as highly concerned about masculine fashion codes manifests itself in the prominent use of material processes in King's question, which accounts for the actions and practices associated with dressing in a certain manner (The sight of Hugh Grant wearing his formal spread-collar shirts, tie-less and open to the sternum really ruined my enjoyment of Notting Hill; My girlfriend, on the other hand, wants me to adopt the same "louche" look; I always thought only buttoned-down shirts could be worn open at the neck) ${ }^{7}$. Such a deep interest in masculine dressing codes is likewise accomplished on the basis of mental processes reproducing the reader's emotional dilemma regarding the correct way of wearing shirts (I always thought only buttoned-down shirts could be worn open at the neck). The relational process by means of which King calls into question the suitability of his own beliefs (Am I right?) contributes to this composition of the reader as well.

On the other hand, $G Q$ counsellor's answer is also fundamental in the construction of men as remarkably keen on dressing conventions. The use of existential processes (there are several open-collar shirt looks that are acceptable), and, particularly, the remarkable abundance of relational processes ( $\mathrm{No}$, you're wrong; Although it is true to say; there are 
several open-collar shirt looks that are acceptable; The most usual is the casual weekend shirt with button cuffs; the louche look you describe is back in a big way; Obviously, the wearer needs to be sleek, slim and sexy), serve to describe such standards. In such relational processes, attributes (e.g. wrong; true; usual; acceptable; sleek, slim and sexy) incorporate an evaluative interpretation of what may be regarded as appropriate or inappropriate ways of dressing for a man, who is illuminatingly depicted as a wearer ${ }^{8}$. Admittedly, a number of material processes in the reply echo specific male performances with regard to fashion (ties should never be worn with button-down shirts; This style was largely hatched in languorous Gucci advertising campaigns, but has now been adopted across the market; your girlfriend thinks you fulfil these criteria). Moreover, it is significant that, both in the question and the answer, the reader's girlfriend is constructed as a senser of mental processes expressing her opinions and wishes about her partner's dressing codes (My girlfriend, on the other hand, wants me to adopt the same "louche" look; you should be grateful that your girlfriend thinks you fulfil these criteria $)^{9}$.

The relevance of menswear conventions in the course of men's social activity is remarkably reflected in the use of passive constructions to represent the informational priorities of the text $t^{10}$. Thus, the deletion of 'men' - albeit easily identifiable by readers as the agent of the clause goes hand in hand with the emphasis placed on various male fashion artefacts (buttoned-down shirts; ties; this style) which are thematized in a prominent position at the beginning of clauses (only buttoned-down shirts could be worn open to the neck; ties should never be worn with button-down shirts; this style [...] has now been adopted across the market). As it is, negation functions suppressing dressing practices on the part of men which are deemed unacceptable (ties should never be worn with buttondown shirts) ${ }^{11}$.

The use of various features of deontic modality in the text evidences the construction of masculine dressing codes as subject to strict regulation, whose mastery and fulfilment triggers men's anxiety ${ }^{12}$. Permission plays a major role in the reader's question itself, for he wonders about the types of shirts which may be worn in a certain way (I always thought only buttoned-down shirts could be worn open at the neck). In addition, the counsellor does not hesitate to draw upon forms of obligation (Although it is true to say that ties should never be worn with button-down shirts, there are several open-collar shirt looks that are acceptable), and necessity (Obviously, the wearer needs to be sleek, slim and sexy for the effect to work), when explaining the norms governing menswear rules. Such a modality marker of obligation as should is also employed by the magazine counsellor to make the reader aware of the validity of his girlfriend's opinion on the subject (and I think you should be grateful that your girlfriend thinks you fulfil these criteria). The use of the pronoun you by the magazine counsellor is significant in this respect, since the second-person meaning dominating the majority of its occurrences in the text to make reference to the reader writing in (No, you're wrong; the louche look you describe is back in a big way) coexists with a case combining the second-person reference with a generic meaning projecting the idea that all men should attach more importance to women's views about such a dimension as masculine fashion (and I think you should be grateful that your girlfriend thinks you fulfil 
these criteria) ${ }^{13}$.

Finally, several aspects of textual cohesion may also shed light on the extent to which men like this reader experiment feelings of uneasiness about personal looks, and the importance which they attach to women in causing a certain anxiety when they question their partners' assumptions about masculine fashion. Forms of comparative reference like the same reveal King's girlfriend's wish for her boyfriend to adopt the way of dressing of famous male icons like Hugh Grant (My girlfriend, on the other hand, wants me to adopt the same "louche" look). The profusion of adversative and concessive connectors expressing contrast is highly significant of the existence of many different - and frequently opposite - male dressing codes which trigger many men's unease and sense of loss (Although it is true to say that ties should never be worn with button-down shirts, there are several open-collar shirt looks that are acceptable; This style was largely hatched in languorous Gucci advertising campaigns, but has now been adopted across the market; However, thanks to the recent wave of Sixties and Seventies nostalgia - and the reappearance of the male cleavage into polite society - the louche look you describe is back in a big way). Lexical-cohesion devices like repetition (wear/wearing/worn [four times]; shirt(s) [five times]; ties [twice]; look(s) [three times]; louche [twice]; button-down [twice]), antonyms (right/wrong) and near synonyms (open at the neck/open-collar), emphasize men's distress about such an aspect of menswear as the most appropriate way of wearing shirts.

\subsection{Interpreting identity construction as a form of interaction}

The choice of textual features described may be interpreted as constructing a discursive practice revolving around men's preoccupation with fashion and male dressing codes, and women's firm attempts to have their views about this matter considered. This type of discourse is articulated following the conventions of counselling columns as a print-media genre. Given the inclusion and publication of an individual consultation in the problem page of a men's magazine, an instance of counselling discourse such as the interaction between the reader having written in and the counsellor acquires the massive diffusion which is characteristic of media discourse. In drawing upon the schema of the problem page as a genre, where an individual demands advice from the expert of a periodical publication to overcome personal troubles, magazine readers will come to comprehend men's relation with fashion as problematic ${ }^{14}$. The editorial board of $G Q$ problem column may be said to have included this question - and answer - insofar as representative of the system of values and concerns of the magazine's ideal male readers. Following quite a common editorial practice echoed by McCracken (1993: 57) with reference to the sister genre of women's magazines, the reader's original question may have been manipulated - or even artificially created - to be consistent with the magazine ideological policy. Therefore, reading the counselling page certainly becomes an act of negotiation of individual readers' identity with the belief systems associated with the meaning of masculinity as projected from the magazine $^{15}$. The great consumption of men's magazines like $G Q$ - and others like $F H M$, 
Maxim or Arena - accounts for the high distribution and circulation of the subject positions or images of masculinity which are promoted amongst male readers from print-media sections like problem columns in Britain.

The discursive practice taking shape thanks to the interaction among the participants articulating this counselling column constructs a subject position where ideal male readers are assumed to be enthusiastic about adopting correct dressing styles, not only to please themselves but also their partners. In exploring the function of personal looks in the construction of identities, Negrin claims that "in the present age self-identity has increasingly been defined in terms of one's physical appearance" (1999: 110), and Silverman underlines the fundamental role of menswear regulations in such identityconstruction processes, since "clothing not only draws the body so that it can be seen, but also maps out the shape of the ego" (1986: 139-140). The sample incorporates direct intertextual references to masculine menswear firms like Gucci (This style was largely hatched in languorous Gucci advertising campaigns, but has now been adopted across the market), and the performance of actors like Hugh Grant in Notting Hill (The sight of Hugh Grant wearing his formal, spread-collar shirts, tie-less and open to the sternum really ruined my enjoyment of Notting Hill ${ }^{16}$. Such allusions reveal the existence of different models which come to constitute a consistent subject position which characterizes a type of man attaching so much importance to dressing regulations.

This dimension of the 'new man' discourse may be claimed to engender a key subject position for individual readers as far as their relation with fashion and dressing codes is concerned ${ }^{17}$. As Nixon sees it, the "regime of looking was central to the distinctiveness of the 'new man' imagery as a whole" (1996: 201). Thus, GQ presumes the existence of many other men who are highly worried about their personal looks, and experiment personal conflicts about their way of dressing, similarly to the 'new man' emerging from this type of discourse. As various textual features have highlighted above, such conflicts are closely intertwined with a resolute rapprochement with women on the part of the 'new man', who, "invigorated by his enthusiastic embrace of female roles and qualities" (Chapman, 1988: 227), does not hesitate to draw attention to women's opinions, by way of example, in the choice of his clothing. Specific utterances in the text activate presuppositions such as the existence of a market of masculine fashion, where men may choose their dressing options (This style was largely hatched in languorous Gucci advertising campaigns, but has now been adopted across the market); specific criteria which men are to follow to fit in with trends in fashion (you should be grateful that your girlfriend thinks you fulfil these criteria); and men willing to subject themselves to such standards (Obviously, the wearer needs to be sleek, slim and sexy for the effect to work ${ }^{18}$.

\subsection{Explaining 'newmannism' as a socio-cultural practice}

The ideological repertoire underlying the construction of masculinity which emerges from the discursive practice articulated in $G Q$ counselling column is in harmony with the 'new man', his preoccupation with personal looks and fashion, and his deeper consideration of 
women's demands and concerns. In an attempt to explain the social matrix of cultural practices representing this new image of masculinity in such popular-culture genres as this magazine, it is imperative to take into account the 'crisis' of traditional masculinity models triggered by the socio-economic changes and the feminist challenges of the past decades. In Edley and Wetherell's view, "the emergence of the 'new man' as a cultural frame of reference has been linked to changes in other social and economic practices [...] a further (overdetermining) factor is the feminist movement and its critique of men and male psychology" (1997: 204). Insofar as an essentially media-driven phenomenon, the construction of the 'new man' in the discursive practices constituted in the problem pages of men's magazines like $G Q$ is inextricably intertwined with the commercial success of these periodicals in the UK, very much in response to the same socio-economic threats to masculinity. According to Jackson et al.,

as men have been encouraged to 'open up' previously repressed aspects of their masculinities, they face a growing sense of anxiety and risk to which the magazines have responded by providing a form of 'constructed certitude' $[. .$.$] a kind of cultural comfort zone, giving men$ the discursive resources to handle their changing circumstances and experiences (2001: 156).

As exemplified in the type of discourse analysed, specific situations within the institutional setting of life in couple evidence women's stronger positions in society, and masculine anxieties as a result. In calling into question her partner's beliefs about male fashion and attempting to impose hers, Bruce A. King's girlfriend substantiates women's deeper selfconfidence and power in gender relations. In actual fact, rather than rejecting King's girlfriend's beliefs, $G Q$ counsellor endeavours to make the reader accept the appropriateness of her assumptions about masculine dressing codes in accordance with the "new man"s "willingness to criticize his own practices" (Hearn and Morgan, 1990: 16). On the other hand, this discourse on masculinity is socially determined by the impact of consumerism on men over the last decades of the twentieth century, which tendency is highly materialized in men's increasing preoccupation with fashion in British society. This is consistent with the prominence of fashion pages in successful men's magazines like $G Q$, as Wernick announced by the late eighties:

It is clear that the recent rise of fashion magazines like Gentlemen's Quarterly [GQ] has been aided by the growth of demand from below. But consumerization, here, is not just a matter of attending to products: what the glossy pages of every current male-oriented consumer magazine make clear is that the more intensively men have entered into competitive circulation, the more they have become, like women before them, analogous to consumer goods themselves (1987: 295).

\section{Conclusions}

As Barker's (2004: 42) definition of cultural studies highlights above, cultural studies may only be understood as an interdisciplinary field of enquiry, which has taken shape by 
incorporating work from different disciplines contributing to examining the constitution of cultural practices. Given the central role of discourse and language in cultural studies, discourse analysis resources may act as a key instrument for this field, taking especially into account that discourse analysis "has stressed the interdisciplinary nature of its research since its beginning" (Weiss and Wodak, 2003: 1). This is particularly the case of critical discourse analysis, which, as a research programme, consists of different theoretical and methodological approaches.

While often invoking discourse as a key element in the construction of cultural practices, cultural studies has barely engaged in detailed textual analyses of actual discourse, which has led cultural theorists like Barker to recommend learning from disciplines such as discursive psychology and critical discourse analysis "by deploying the tools of micro-linguistic analysis to show just how 'social construction' is achieved in the flow of everyday speech and interaction" (2002: 44). As it is, many discourse analysis theorists and practitioners are aware that considering language as discourse - a basic tenet of CDA - will turn out to be highly beneficial for non-linguistic disciplines like cultural studies, opening up "countless new areas for the critical investigation of social and cultural life - the composition of cultural groups, the management of social relations, the constitution of social institutions, the perpetuation of social prejudices, and so on" (Jaworski and Coupland, 1999: 5).

The practices of representation and construction of images of masculinity - or subject positions - like the 'new man' in popular-culture genres such as men's magazines' problem columns in contemporary Britain are fundamentally discursive. CDA has helped us to reveal the role of language in this process of identity construction and its wider sociocultural matrix. Specific linguistic features are determined by the system of values and beliefs characterizing the representation of the 'new man' in Britain, contributing to the configuration of its underlying ideology in cultural artefacts such as problem pages in men's magazines as well. As the case study has closely examined, in addition to $G Q$ reader's desire to verify his girlfriend's views about masculine dressing codes, his own concern about that matter is consistent with the ideological apparatus of the 'new man', including his preoccupation with fashion and his attempts to satisfy female demands. Various textual features (lexis, verbal processes, passive voice, negation, modality, textual cohesion, presupposition, etc.) reflect this ideology, and help to construct the type of discourse articulated in $G Q$ magazine's problem page. This discursive practice involves the interaction between the individual reader writing in, $G Q$ counsellor, this section's editorial board and the plurality of magazine consumers. The construction of this type of discourse is part of the cultural practices of representation of masculinity in men's magazines and their commodification of men's gender anxieties regarding such dimensions as the impact of consumerism on men or the feminist challenges to patriarchal gender relations.

In short, CDA has shed light on the discursive construction of such a subject position as the 'new man' by integrating the strictly textual component of the discourse on masculinity where it is articulated into the wider socio-cultural dimension in which it is embedded via the mediated interaction process which is characteristic of men's magazines' 
counselling columns as a media-discourse genre in Britain. It seems to be obvious that a larger number of texts should have been examined so as to conclude that the construction of the 'new man' in the problem pages of British men's lifestyle magazines like $G Q$ regularly manifests the linguistic features revealed by this analysis ${ }^{19}$. The aim of this paper has been rather to highlight the efficiency of CDA as an analytical instrument for cultural analysis on the basis of a case study. This individual analysis has allowed us to explore the discursive construction of the 'new man' in a thorough way. This process might not have been observed in such a detailed manner by examining a large number of samples, which could not have been reproduced in the form of an appendix at the end of the paper.

\section{Notes}

1. In fact, quoting the work of Slembrouck (2001), Blommaert (2005: 23) draws attention to the influence of British Cultural Studies upon the constitution of CDA, particularly in the case of Fairclough's (1989, 1992, 1995a, 1995b, 2003) CDA work.

2. Du Gay et al. explain this intrinsic relation between language and culture in society on the basis of the representational function of language: "Culture, then, is inextricably connected with the role of meanings in society. It is what enables us to 'make sense' of things. But how does this 'meaning-making' work? Partly, we give things meanings by the way we represent them, and the principal means of representation in culture is language" (1997: 13).

3. Similarly to Davies and Harré's characterization of subject positions "in terms of the particular images, metaphors, story lines and concepts which are made relevant within the particular discursive practice in which they [individuals] are positioned" (1990:46), from a cultural studies perspective Barker describes this concept as "empty spaces or functions in discourse from which the world makes sense" (2002: 227).

4. The concept of 'negotiation' makes reference to the process whereby individuals adopt, or resist, the systems of values and beliefs incorporated by specific subject positions. As Mills puts it, "individual subjects should not be simply seen to adopt roles which are mapped out for them by discourses; rather, they experience discomfort with certain elements implicit in discourses, they find pleasure in some elements, they are openly critical about others" (1997: 97).

5. See Fairclough and Wodak (1997) or Wodak and Meyer (2001) for detailed overviews of different approaches to CDA.

6. According to Fairclough, every text, however short it may be, counts as a form of discourse incorporating its three constitutive dimensions, to wit, text, discursive interaction and sociocultural practice: "any part of any text can fruitfully be examined in terms of the co-presence and interaction of these constitutive processes" (1995a: 6). Fairclough (1989: 172-196) himself analyses the construction of different subject positions by utilizing specific textual samples; that is the case of the discourse of Thatcherism on the basis of a radio interview.

7. According to systemic-functional linguistics, our perception of reality is constructed in the form of 'goings-on' or processes involving different participants. Halliday's (1994) taxonomy includes material processes, which have to do with the world of acting and creating (e.g. go, run, take); mental, related to sensing and the world of consciousness (e.g. like, want, hear); relational, which refer to being and becoming (e.g. be, have, become); existential, which represent that something exists or happens (e.g. exist, happen, rain); verbal, which are processes of saying (e.g. say, suggest, advise); and behavioural, which are typical of physiological or psychological human 
behaviour (e.g. cry, dream, cough).

8. According to Halliday (1994: 120), in addition to the process itself, relational processes may include an identified participant (carrier) and an attribute (e.g. Sarah [carrier] is [process] wise [attribute]).

9. In mental processes, "the Senser is the conscious being [participant] that is feeling, thinking or sensing" (Halliday, 1994: 117).

10. As Hodge and Kress stress, "the passive with a deleted actor [...] creates an impression of objectivity through the impersonality of the language" (1993: 134). Together with this personalization-suppression strategy, placing affected elements in initial clause position through the passive "allows a writer or a speaker to emphasize his thematic priorities, to emphasize what the text is 'about' even when the entities of the theme are, strictly speaking, semantically subordinate (affected rather than agentive)" (Fowler and Kress, 1979: 209).

11. As Hodge and Kress metaphorically express, "a negative is a convenient way of expressing forbidden meaning, evading a censor by the vehemence of the denial" (1993: 146). Fairclough adds in this respect that "negative sentences carry special types of presupposition which also work intertextually, incorporating other texts only in order to contest them or reject them" (1992: 121-122).

12. According to Crystal, "deontic modality is concerned with the logic of obligation and permission" (1997: 109).

13. As stated by Quirk et al., "[generic] you again retains something of its 2 nd person meaning: it can suggest that the speaker is appealing to the hearer's experience of life in general, or else of some specific situation, as in: This wine makes you feel drowsy, doesn't it?" (1985: 354).

14. Following Brown and Yule, schemata may be said to be "higher-level complex (and even conventional or habitual) knowledge structures', which function as 'ideational scaffolding' in the organisation and interpretation of experience" (1983:247).

15. As examined above, discourse in general produces subject positions serving individuals to construct their identity. In particular, media discourse constructs a special type of subject positions, labelled as 'ideal readers' by authors like Reah (1998: 40), over whom a certain system of values and beliefs is presupposed. Exploring the role of men's and women's magazines in the construction of gender identities, McLoughlin argues that "magazines are a means of presenting ideal-reader images to which the purchaser can aspire" (2001: 95).

16. As a matter of fact, "it was through the presentation of these menswear designs in popular representations that the 'new man' was often coded" (Nixon, 1997: 295).

17. As Warde maintains, identity has become a matter of choice nowadays, since "people define themselves through the messages they transmit to others through the goods and practices that they possess and display. They manipulate or manage appearances and thereby create and sustain a 'self-identity'. In a world where there is an increasing number of commodities available to act as props in this process, identity becomes more than ever a matter of the personal selection of selfimage" (1994: 878).

18. Yule defines a presupposition as "something that the speaker assumes to be the case prior to making an utterance" (1996: 25).

19. In a different work (de Gregorio-Godeo, 2003), we explore the discursive construction of masculinities in British men's magazines' problem pages as a genre, and we provide detailed quantitative data regarding a wider corpus of analysis. 


\section{References}

Baldwin, Elaine et al. (1999): Introducing Cultural Studies. London: Prentice Hall Europe. Barker, Chris (2002): Making Sense of Cultural Studies. Central Problems and Critical Debates. London: Sage. . (2004): The Sage Dictionary of Cultural Studies. London: Sage.

Barker, Chris and Dariusz Galasinski (2001): Cultural Studies and Discourse Analysis. A Dialogue on Language and Identity. London: Sage.

Bennett, Tony (1998): Culture: a Reformer's Science. London: Sage.

Benwell, Bethan (2003): "Introduction: masculinity and men's lifestyle magazines". In B. Benwell, ed., Masculinity and Men's Lifestyle Magazines. Oxford: Blackwell, 6-29.

Blommaert, Jan (2005): Discourse. Cambridge: Cambridge University Press.

Branston, Gill and Roy Stafford (1996): The Media Student's Book. London/New York: Routledge.

Brown, Gillian and George Yule (1983): Discourse Analysis. Cambridge: Cambridge University Press.

Caldas-Coulthard, Carmen Rosa (1996): “'Women who pay for sex. And enjoy it'. Transgression versus morality in women's magazines". In C.R. Caldas-Coulthard and M. Coulthard, eds., Texts and Practices. Readings in Critical Discourse Analysis. London: Routledge, 250-270. Chapman, Rowena (1988): "The great pretender: variations on the New Man theme". In R. Chapman and J. Rutherford, eds., Male Order. Unwrapping Masculinity. London: Lawrence \& Wishart, 225-248.

Chouliaraki, Lilie and Norman Fairclough (1999): Discourse in Late Modernity. Rethinking Critical Discourse Analysis. Edinburgh: Edinburgh University Press.

Crystal, David (1997): A Dictionary of Linguistics and Phonetics. Oxford: Blackwell.

Davies, Bronwyn and Rom Harre (1990): "Positioning: the discursive production of selves". Journal for the Theory of Social Behaviour 20(1): 43-63.

de Gregorio-Godeo, Eduardo (2003): La construcción de la identidad masculina en el discurso de la sección de consulta de las revistas de interés general para hombres en el Reino Unido. Cuenca: Servicio de Publicaciones de la Universidad de Castilla-La Mancha.

du Gay, Paul et al. (1997): Doing Cultural Studies. The Story of the Sony Walkman. London: Sage/The Open University.

During, Simon (1993): "Introduction". In S. During, ed., The Cultural Studies Reader. London/New York: Routledge, 1-25.

Edgar, Andrew and Peter Sedgwick (eds.) (1999): Key Concepts in Cultural Theory. London/New York: Routledge.

Edley, Nigel and Margaret Wetherell (1997): "Jockeing for position: The construction of masculine identities". Discourse \& Society 8(2): 203-217.

Edwards, Tim (1997): Men in the Mirror. Men's Fashion, Masculinity and Consumer Society. London: Cassell.

Fairclough, Norman (1989): Language and Power. London: Longman. . (1992): Discourse and Social Change. Cambridge: Polity.

Longman.

(1995a): Critical Discourse Analysis: the Critical Study of Language. London: (1995b): Media Discourse. London: Edward Arnold. 
. (2000): New Labour, New Language? London: Routledge.

(2001) [1989]: Language and Power, $2^{\text {nd }}$ ed. Harlow: Longman.

. (2003): Analysing Discourse. Textual Analysis for Social Research. London: Routledge.

Fairclough, Norman and Ruth Wodak (1997): "Critical discourse analysis". In T. van Dijk, ed., Discourse as Social Interaction. London: Sage, 258-284.

Fowler, Roger and Gunther Kress (1979): "Critical linguistics". In R. Fowler et al., eds., Language and Control. London: Routledge \& Kegan Paul, 185-213.

Grossberg, Lawrence (1997): Bringing It All Back Home: Essays on Cultural Studies. Durham: Duke University Press.

Hall, Stuart (1997): "Introduction". In S. Hall, ed., Representation. Cultural Representations and Signifying Practices. London: Sage/The Open University, 1-11.

. (2000): "Who needs 'identity'?" In P. du Gay et al., eds., Identity: a Reader, Sage/The Open University, 15-30.

Halliday, M.A.K. (1994) [1985]: An Introduction to Functional Grammar. London: Edward Arnold.

Hearn, Jeff and David H.J. Morgan (1990): "Men, masculinities and social theory". In J. Hearn and D.H.J. Morgan, eds., Men, Masculinities and Social Theory. London: Unwyn Hyman, 3-36.

Hodge, Robert and Gunther Kress (1993): Language as Ideology. London/New York: Routledge. Jackson, Peter et al. (2001): Making Sense of Men's Magazines. Cambridge: Polity.

Jaworski, Adam and Nikolas Coupland (1999): "Perspectives on discourse analysis". In A.

Jaworski and N. Coupland, eds., The Discourse Reader. London/New York: Routledge, 1-44.

Lewis, Jeff (2002): Cultural Studies - The Basics. London: Sage.

Martín Rojo, Luisa et al. (1998): "El análisis crítico del discurso: una mirada indisciplinada". In

L. Martín Rojo and R. Whittaker, eds., Poder-decir o el poder de los discursos. Madrid:

Arrecife/The British Council/U.A.M., 9-33.

McCracken, Ellen (1993): Decoding Women's Magazines. New York: St. Martin's Press.

McLoughlin, Linda (2000): The Language of Magazines. London/New York: Routledge.

Mills, Sarah (1997): Discourse. London/New York: Routledge.

Mort, Frank (1988): "Boy's own. Masculinity, style and popular culture". In R. Chapman and J. Rutherford, eds., Male Order: Unwrapping Masculinity. London: Lawrence \& Wishart, 193-224.

Negrin, Llewellyn (1999): "The self as image. A critical appraisal of postmodern theories of fashion". Theory, Culture and Society 16(3): 99-118.

Nixon, Sean (1996): HardLooks. Masculinity, Spectatorship \& Contemporary Consumption. New York: St. Martin's Press.

. (1997): "Exhibiting masculinity". In S. Hall, ed., Representation. Cultural Representations and Signifying Practices. London: Sage/The Open University, 291-330.

Phillips, Louise and Marianne Jørgensen (2002): Discourse Analysis as Theory and Method. London: Sage Publications.

Quirk, Randolph et al. (1985): A Comprehensive Grammar of the English Language. Harlow: Longman.

Reah, Danuta (1998): The Language of Newspapers. London/New York: Routledge.

Silverman, Kaja (1986): "Fragments of a fashionable discourse". In T. Modleski, ed., Studies in Entertainment. Bloomington/Indianapolis: Indiana University Press, 139-152. 
Slembrouck, Stef (2001): "Explanation, interpretation and critique in the analysis of discourse". Social Anthropology 21: 33-57.

Smith, Phillippa (ed.) (1996): Men's Magazines. Market Report. Hampton: Key Note.

Sunderland, Jane (2004): Gendered Discourses. Houndmills, Basingstoke: Palgrave. van Dijk, Teun (1991): Racism and the Press. London: Routledge.

. (2001): "Critical discourse analysis". In D. Schiffrin et al., eds., The Handbook of Discourse Analysis. Oxford: Blackwell, 352-371.

Warde, Alan (1994): "Consumption, identity-formation and uncertainty". Sociology 28(4): 877898.

Weiss, Gilbert and Ruth Wodak (2003): "Introduction: theory, interdisciplinarity and critical discourse analysis". In G. Weiss and R. Wodak, eds., Critical Discourse Analysis. Theory and Interdisciplinarity. Houndmills, Basingstoke: Palgrave Macmillan, 1-32.

Wernick, Andrrew (1987): "From voyeur to narcissist: imaging men in contemporary advertising". In M. Kaufman, ed., Beyond Patriarchy: Essays by Men on Pleasure, Power and Children. Toronto/New York: Oxford University Press, 277-297.

Wodak, Ruth (2001): "What CDA is about - a summary of its history, important concepts and its developments". In R. Wodak and M. Meyer, eds., Methods of Critical Discourse Analysis. London/New York: Sage Publications, 1-13.

Wodak, Ruth and Christopher Ludwig (1999): "Introduction". In R. Wodak and C. Ludwig, eds., Challenges in a Changing World. Issues in Critical Discourse Analysis. Vienna: PassagenVerlag, 11-19.

Wodak, Ruth et al. (1999): The Discursive Construction of National Identity. Edinburgh: Edinburgh University Press.

Wodak, Ruth and Michael Meyer (eds.) (2001): Methods of Critical Discourse Analysis. London/New York: Sage Publications.

Yule, George (1996): Pragmatics. Cambridge: Cambridge University Press.

\section{Appendix: Sample Analysed (GQ, August 1999, p. 168)}

Q. The sight of Hugh Grant wearing his formal, spread-collar shirts, tie-less and open to the sternum really ruined my enjoyment of Notting Hill. My girlfriend, on the other hand, wants me to adopt the same "louche" look. I always thought only buttoned-down shirts could be worn open at the neck. Am I right?

Bruce A King, not quite Notting Hill

A. No, you're wrong. Although it is true to say that ties should never be worn with button-down shirts, there are several open-collar shirt looks that are acceptable. The most usual is the casual weekend shirt with button cuffs, perhaps made in an Oxford cotton. However, thanks to the recent wave of Sixties and Seventies nostalgia - and the reappearance of the male cleavage into polite society - the louche look you describe is back in a big way. This style was largely hatched in languorous Gucci advertising campaigns, but has now been adopted across the market. Obviously, the wearer needs to be sleek, slim and sexy for the effect to work and I think you should be grateful that your girlfriend thinks you fulfil these criteria. 